Terr. Atmos. Ocean. Sci., Vol. 18, No. 4, 757-776, October 2007

\title{
Correlations Between Erosions and Relative Uplifts From the Central Inversion Zone of the Xihu Depression, East China Sea Basin
}

\author{
Chun-Feng Li ${ }^{1,2, *}$, Zuyi Zhou ${ }^{1,2}$, Heping Ge ${ }^{3}$, and Yunxin Mao ${ }^{3}$
}

(Manuscript received 8 December 2006, in final form 16 April 2007)

\begin{abstract}
Late Pliocene - early Pleistocene erosions and relative uplifts in the central inversion zone of the Xihu Depression, East China Sea Basin, are independently determined from reflection seismic data and sonic well-logging data, respectively. Relative uplifts estimated from linear least-square models of 26 sonic wells range from 0.0 to $501.3 \mathrm{~m}$, while absolute erosions estimated on their respective well localities are generally larger, in the range of $\sim \mathbf{5 0 . 0}$ to $\mathbf{1 1 4 7 . 5} \mathrm{m}$ measured directly from seismic data, and $\sim \mathbf{7 0 . 0}$ to $1700.4 \mathrm{~m}$ after decompaction. Although discrepancies exist for several of the wells, a strong positive correlation can be found between erosions and relative uplifts. This good correlation verifies on the one hand that sonic well-logging data can give reasonably good estimates of relative uplifts, and on the other hand that erosions incurred during the basin inversion are strongly tectonically driven. Erosions and relative uplifts appear to be more exponentially than linearly interrelated.
\end{abstract}

(Key words: East China Sea Basin, Xihu Depression, Erosion, Uplift, Basin inversion, Sonic logging, Cross correlation)

\section{INTRODUCTION}

Erosion and uplift are two basic geological processes associated with mountain building, and there has been an upsurge of interests in better understanding the complex and dynamic

\footnotetext{
${ }^{1}$ School of Ocean and Earth Sciences, Tongji University, Shanghai, China

2 State Laboratory of Marine Geology, Tongji University, Shanghai, China

${ }^{3}$ CNOOC China Limited-Shanghai, Shanghai, China

* Corresponding author address: Dr. Chun-Feng Li, School of Ocean and Earth Sciences, Tongji University, Shanghai, China; E-mail: cfl@mail.tongji.edu.cn
} doi: 10.3319/TAO.2007.18.4.757(TT) 
feedbacks between tectonics, climate, and denudation (i.e., Wobus et al. 2005). However the exact relationships and interactions between erosion and uplift are often difficult to quantify due to the lack of observable or measurable data. Most studies on uplift and erosion are focused on present-day landscapes, such as the Sierra Nevada (Riebe et al. 2000; Cecil et al. 2006), the Colorado Plateau (Pederson et al. 2002) and the Tibetan Plateau (Wobus et al. 2005), which can offer easy access and direct measurements. Cosmogenic isotopes such as ${ }^{26} \mathrm{Al}$ and ${ }^{10} \mathrm{Be}$, and low-temperature thermochronology based on apatite and zircon (U - Th) / He ages are two commonly used techniques in estimating erosion and exhumation (Spotila 2005). Riebe et al. (2000) studied the erosion rates in the Sierra Nevada of California using cosmogenic ${ }^{26} \mathrm{Al}$ and ${ }^{10} \mathrm{Be}$, while in the same region, Cecil et al. (2006) studied the Cenozoic exhumation from (U - Th) / He thermochronology. Wobus et al. (2005) suggested from ${ }^{10} \mathrm{Be}$ data that a locus of active deformation well to the north of the Himalayan deformation front has been maintained by dynamic interactions between climate, erosion and tectonics.

Even with sophisticated technology, it has often been very difficult to measure both erosion and uplift at the same locality. Over the past 30 years of petroleum explorations, a dense coverage of reflection seismic lines have been shot, and more than 40 deep wells have been drilled, in the Xihu Depression of the East China Sea Basin (Figs. 1, 2). This large volume of data provides a unique opportunity to quantitatively examine the interplay between uplift and erosion related to tectonic basin inversion at the end of the Pliocene. By using sonic well logging data from numerous industrial wells drilled on the inversion folds, it is possible to estimate the relative uplifts around these inversion folds. Meanwhile, dense multichannel seismic lines provide an independent opportunity for estimating maximum erosions around the folds, by carefully measuring the erosional thicknesses and by identifying syn-inversion strata deposited during the fold growth (Wang et al. 1995; Liu et al. 1999). By cross-examining the erosions and relative uplifts estimated from two independent methods, insights can be gained on their interrelationships, which are often difficult to assess without quantified measurements. This is a study of an ancient case that could offer complimentary insights on our understanding of the present-day relationship between erosion and uplift.

The importance of this study is therefore threefold. First, a quantitative calibration on the erosion and uplift are vital for understanding the Pliocene mountain building processes in the area and for testing various hypotheses on exhumation. Secondly, the magnitudes of erosions are required parameters for accurate basin modeling (Steckler and Watts 1978). Thirdly, erosion, uplift, and related tectono-thermal processes, can have direct influences on hydrocarbon generation and migration.

\section{GEOLOGICAL SETTINGS}

The East China Sea Basin, located on the East China Sea continental shelf, is a Cenozoic continental margin basin bounded to the east by the Diaoyudao Uplift Belt (also named as Taiwan-Sinzi belt, see Kong 1998 and Hsu et al. 2001) and to the west by the Zhemin Uplift Belt (Fig. 1). Within the East China Sea Basin, the southwest-northeast elongated Xihu Depression, together with the Fujiang Depression to its north and the Diaobei Depression 
(also known as Jilong Depression, see Kong 1998 and Hsu et al. 2001) to its south, are the most outstanding features (Fig. 1). Collectively these depressions form a large Cenozoic continental margin rifting system subparallel to the Diaoyudao Uplift Belt, which is an elevated unit showing strong magmatic activities (Kong 1998).

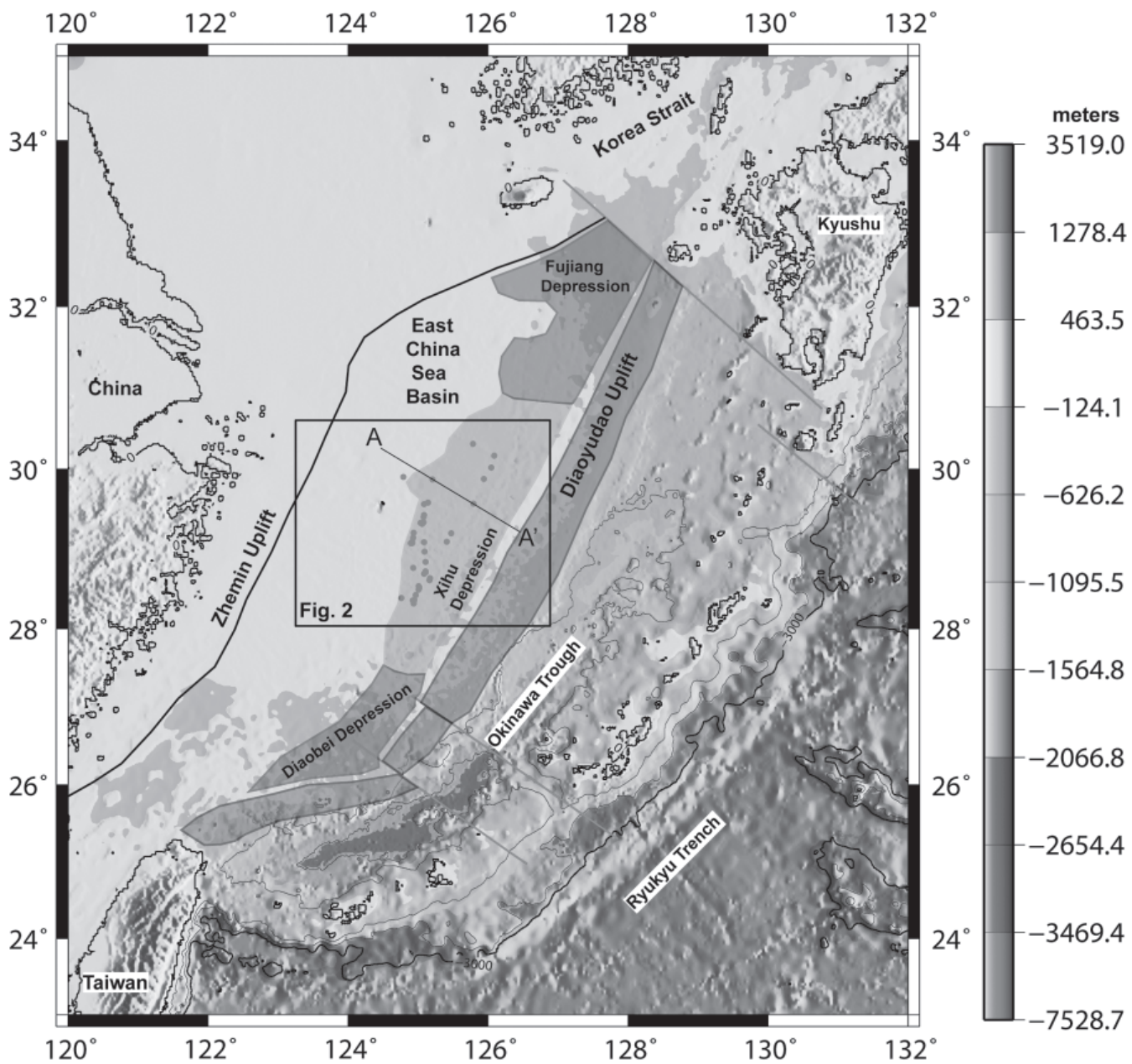

Fig. 1. Color relief map showing the position of the Xihu Depression and major tectonic units in the East China Sea region. Isobaths shown on the map are $0,1000,2000$, and $3000 \mathrm{~m}$, respectively. Red bold straight lines are several major NW-striking faults, and red dots show well locations. The square in the middle outlines the area shown in Fig. 2. AA' is the seismic line shown in Fig. 3. 


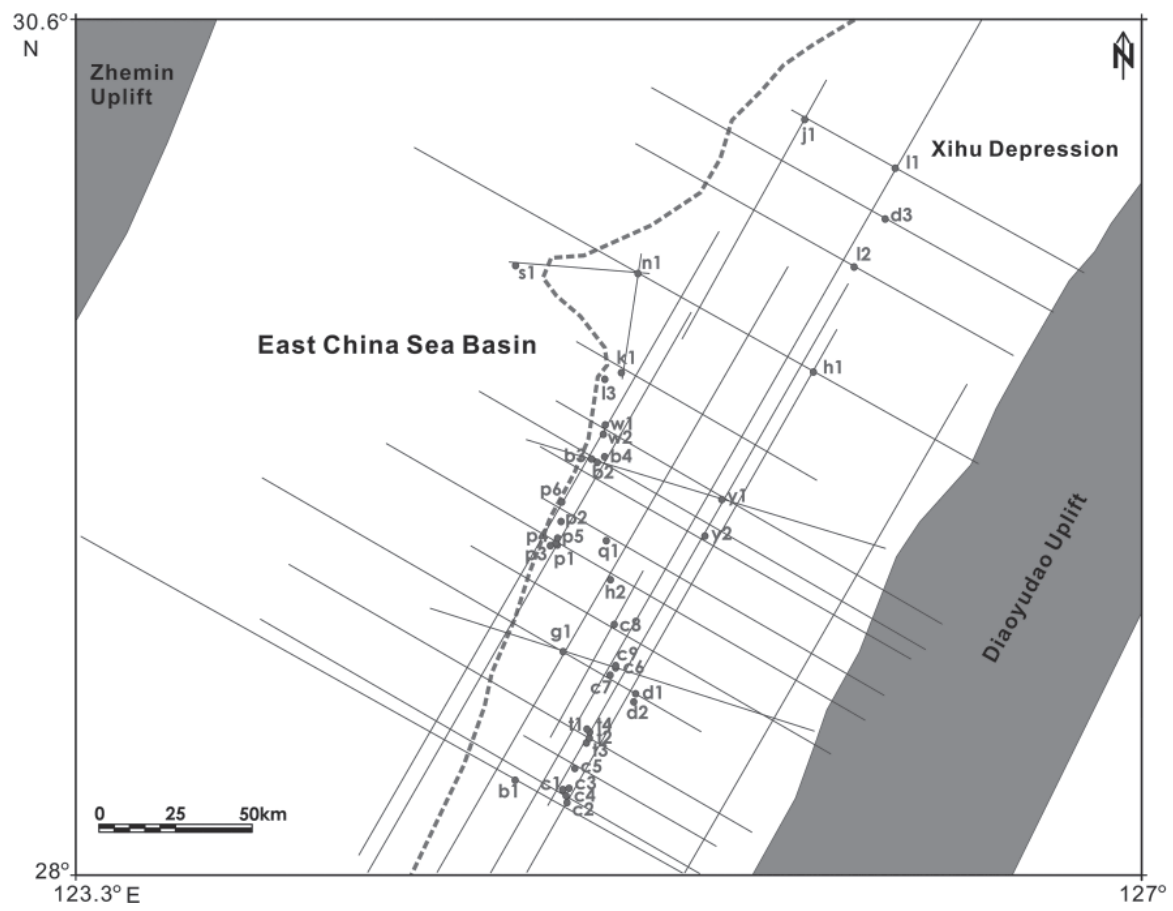

Fig. 2. Map showing the wells and some of the seismic lines passing through wells used in this study. Dashed line shows the western margin of the Xihu Depression.

The Xihu Depression is generally regarded to be formed by the late Cretaceous and early Paleogene continental margin rifting (Wang et al. 1995). It has a full suite of thick Cenozoic sediments of primarily terrestrial sources, with a maximum depth of deposition reaching up to $15 \mathrm{~km}$ (Figs. 3, 4). On seismic sections traversing the Xihu Depression, its basement unconformity $\mathrm{T}_{\mathrm{g}}$ can be clearly identified at about $6.2 \mathrm{~s}$ in two-way travel time (Fig. 3). Transversely the Xihu Depression is about $120 \mathrm{~km}$ wide on average. However, its original width could have been much larger for two reasons. Firstly, its southeastern margin is too severely deformed by magmatic intrusions to be readily identifiable (Fig. 3), and secondly, the Xihu Depression experienced multiphase compressions in the course of subsidence. Episodic transpressional events produced at least four major unconformities recorded by the Cenozoic sediments in the Xihu Depression (Fig. 4). Among these unconformities the late middle Eocene breakup unconformity $\mathrm{T}_{4}{ }^{0}(\sim 40.4 \mathrm{Ma})$ and the late Pliocene inversion unconformity $\mathrm{T}_{1}{ }^{0}(\sim 5.23 \mathrm{Ma})$ are the two most important ones as they also serve as boundaries of three major tectonic sequences (Figs. 3, 4). They are the synrift sequence between $\mathrm{T}_{\mathrm{g}}$ and $\mathrm{T}_{4}{ }^{0}$, the postrift sequence between $\mathrm{T}_{4}{ }^{0}$ and $\mathrm{T}_{1}{ }^{0}$, and the open-sea sequence between $\mathrm{T}_{1}{ }^{0}$ and the seabed (Figs. 3 and 4). 
The transpressional tectonic event causing unconformity $\mathrm{T}_{1}^{0}$ is most impressively manifested by a tectonic inversion zone roughly along the southwest-northeast elongational center of the Xihu Depression (Figs. 1, 3). The major phase of tectonic inversion occurred at the end of Miocene. At well h1 on seismic line AA' (Fig. 3), the cross-section of the inversion fold is narrowly spaced compared to the width of the depression. The fold is apparently asymmetric, with a steep northwestern flank and a mild southeastern flank. This folding feature involves a thick sequence of rock layer, ranging in two way travel time from about $1.0 \mathrm{~s}$ to $4.0 \mathrm{~s}$, or equivalently spanning a thickness of about $5800 \mathrm{~m}$ beneath $\mathrm{T}_{1}^{0}$ (Fig. 3). These features reveal that the basin inversion is thick-skinned, as also indicated by Wang et al. (1995).
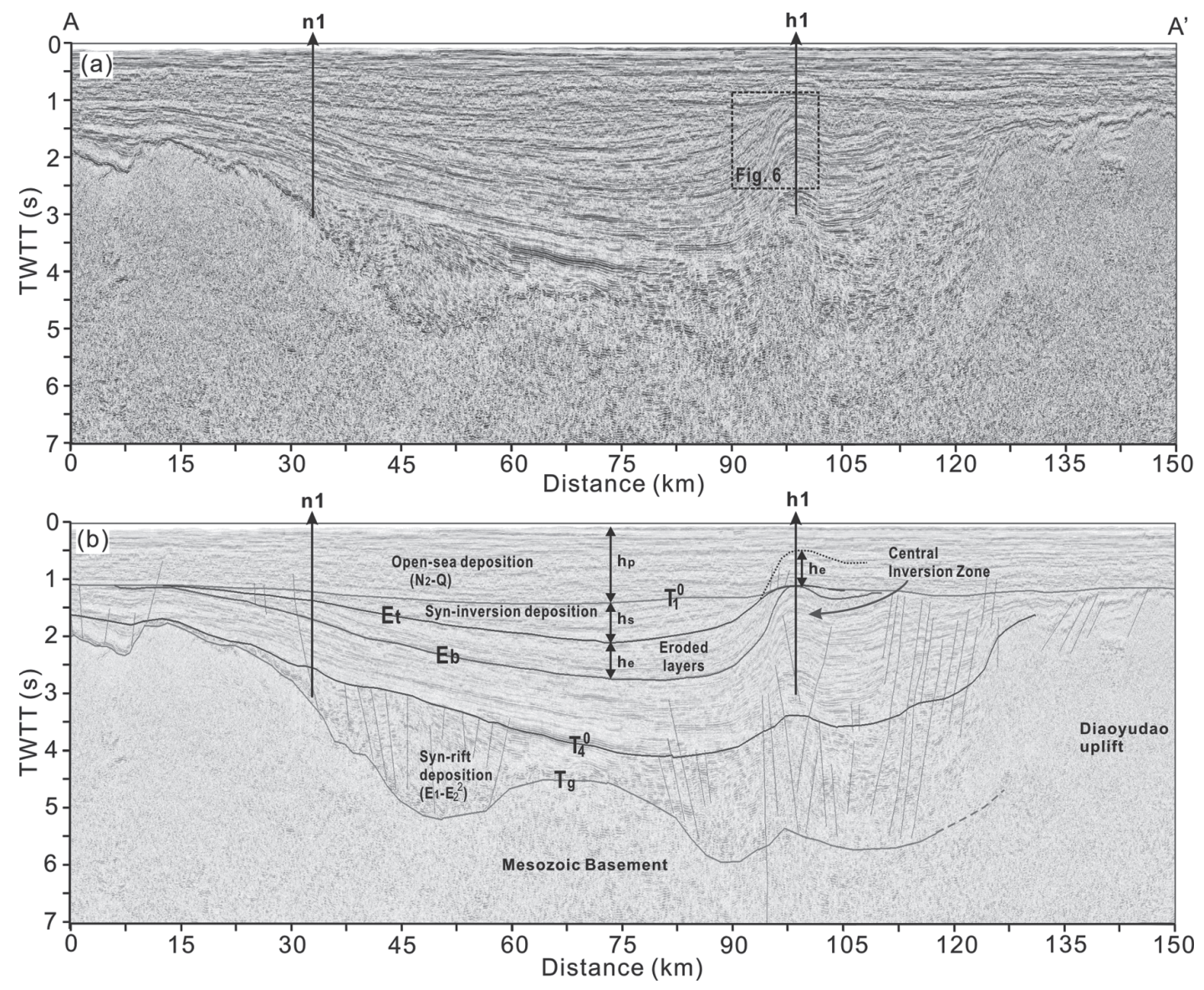

Fig. 3. (a) AA' seismic section passing through wells $\mathrm{h} 1$ and $\mathrm{n} 1$ in the Xihu Depression. (b) Data interpretations of (a). $\mathrm{T}_{\mathrm{g}}=$ basement unconformity; $\mathrm{T}_{4}{ }^{0}=$ breakup unconformity; $\mathrm{T}_{1}{ }^{0}=$ inversion unconformity. $\mathrm{Et}=$ top of eroded strata; $\mathrm{Eb}=$ base of eroded strata; TWTT = two way travel time. 


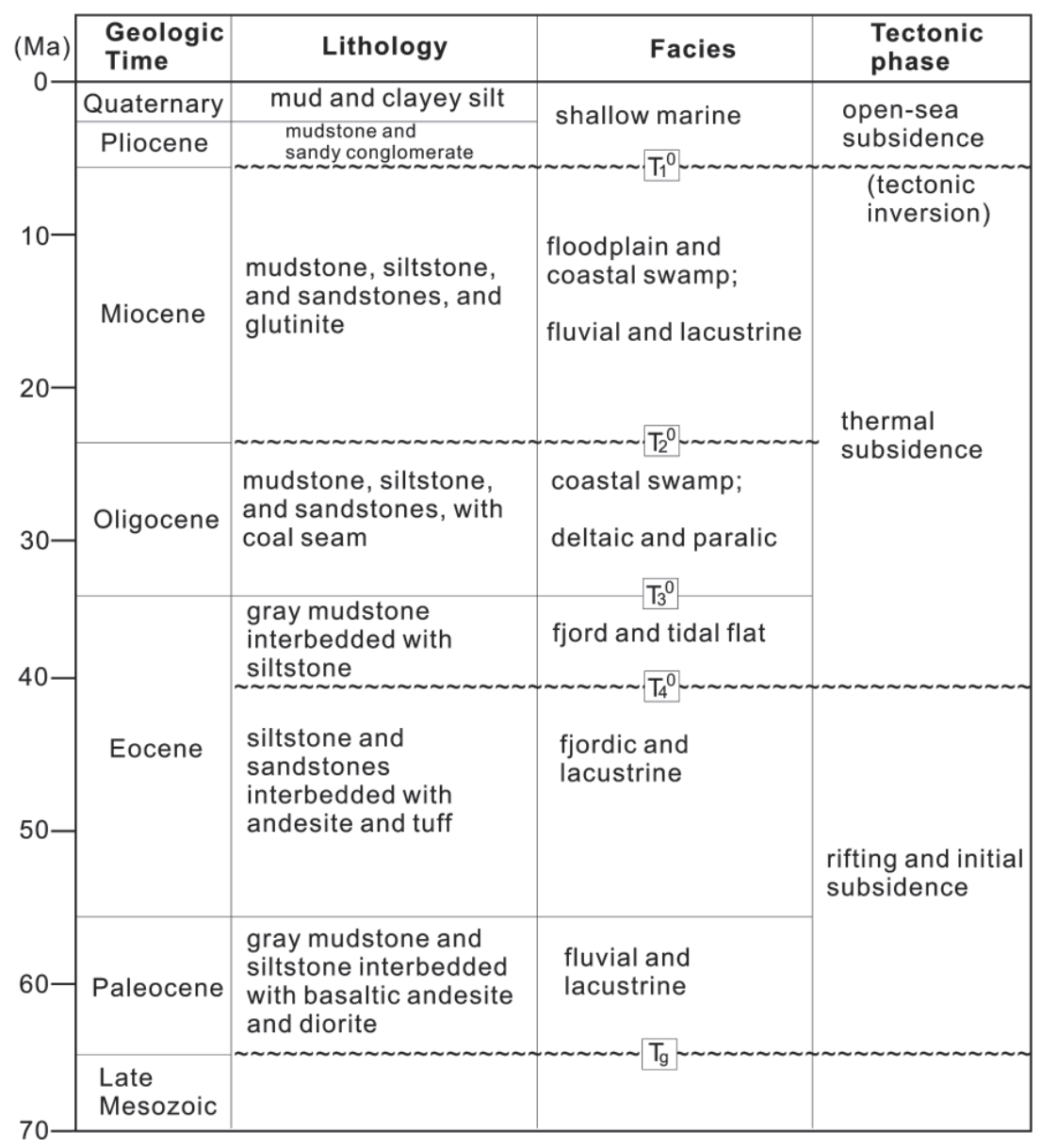

Fig. 4. Schematic stratigraphic sequences and tectonic events in the Xihu Depression (modified from Wang et al. 1995; Liu et al. 1999; Chen and Ge 2003; Wang and Zhang 2005).

\section{DATA}

In this study, we have 26 wells (Table 1) with sonic logging data, and most of these wells are located on the central inversion zone (Figs. 1,2). These well data were acquired by oil companies over a time span of more than two decades, and the first well was drilled in 1980. The sampling interval for sonic data is $0.1 \mathrm{~m}$. The collection of more than $1002 \mathrm{D}$-seismic lines used in this study is also from oil companies. Although these seismic data were acquired and processed or reprocessed over many years by different companies, they followed common industrial standards. In most cases, the shot interval is $25 \mathrm{~m}$, the receiver interval is $12.5 \mathrm{~m}$, 
and the raw sampling rate is 2 ms. Taking line AA' shown in Fig. 3 as an example, it was acquired in 1993 using a 120-channel streamer, with a shot interval of $25 \mathrm{~m}$, a receiver interval of $12.5 \mathrm{~m}$, and a raw sampling rate of $2 \mathrm{~ms}$. The data were rigorously reprocessed in 1999 to improve the quality of deeper reflections.

Table 1. Linear porosity models, relative uplifts and erosions.

\begin{tabular}{|c|c|c|c|c|c|c|}
\hline $\begin{array}{c}\text { Well } \\
\text { names }\end{array}$ & Linear fits & $\mathbf{R}^{2}$ & $\begin{array}{c}\text { Depth }(\mathrm{m}) \\
\text { for } \phi \\
=40 \%\end{array}$ & $\begin{array}{c}\text { Relative } \\
\text { uplifts (m) }\end{array}$ & $\begin{array}{c}\text { Erosion } \\
\text { (m) }\end{array}$ & $\begin{array}{l}\text { Erosion }(m) \mathbf{A} / \\
\text { decompaction }\end{array}$ \\
\hline b1 & $\phi=-0.140 z+0.5957$ & 0.899 & 1397.86 & 163.01 & 322.43 & 476.56 \\
\hline $\mathrm{c} 1$ & $\phi=-0.1185 z+0.5831$ & 0.923 & 1545.15 & 15.718 & $\sim 50.0$ & $\sim 70.0$ \\
\hline c2 & $\phi=-0.1263 z+0.5615$ & 0.919 & 1278.70 & 282.16 & $* *$ & $* *$ \\
\hline $\mathrm{c} 3$ & $\phi=-0.1393 z+0.6170$ & 0.815 & 1557.79 & 3.0767 & $* *$ & $* *$ \\
\hline $\mathrm{c} 4$ & $\phi=-0.1336 z+0.6009$ & 0.829 & 1503.74 & 57.123 & $* *$ & $* *$ \\
\hline $\mathrm{c} 5$ & $\phi=-0.1351 z+0.6076$ & 0.816 & 1536.64 & 24.226 & 114.43 & 167.15 \\
\hline c6 & $\phi=-0.1245 z+0.5747$ & 0.915 & 1403.21 & 157.65 & 284.63 & 399.58 \\
\hline c7 & $\phi=-0.1268 z+0.5610$ & 0.903 & 1269.72 & 291.15 & 95.89 & 136.45 \\
\hline $\mathrm{c} 8$ & $\phi=-0.1109 z+0.5731$ & 0.893 & 1560.87 & 0.0 & 196.41 & 283.28 \\
\hline c9 & $\phi=-0.1193 z+0.5651$ & 0.868 & 1383.91 & 176.96 & 240.54 & 345.89 \\
\hline d1 & $\phi=-0.1328 z+0.5897$ & 0.937 & 1428.46 & 132.40 & 219.94 & 309.07 \\
\hline $\mathrm{d} 2$ & $\phi=-0.1255 z+0.5672$ & 0.916 & 1332.27 & 228.59 & $* *$ & $* *$ \\
\hline g1 & $\phi=-0.1226 z+0.5756$ & 0.930 & 1432.30 & 128.57 & 148.96 & 211.93 \\
\hline h1 & $\phi=-0.1243 z+0.5614$ & 0.917 & 1298.47 & 262.39 & 1147.53 & 1700.4 \\
\hline h2 & $\phi=-0.1098 z+0.5298$ & 0.665 & 1182.15 & 378.72 & $\sim 50.0$ & $\sim 70.0$ \\
\hline $\mathrm{j} 1$ & $\phi=-0.1304 z+0.5953$ & 0.917 & 1497.70 & 63.166 & $\sim 50.0$ & $\sim 70.0$ \\
\hline 12 & $\phi=-0.1174 z+0.5412$ & 0.836 & 1202.73 & 358.14 & 969.30 & 1461.7 \\
\hline $\mathrm{n} 1$ & $\phi=-0.1115 z+0.5648$ & 0.911 & 1478.03 & 82.839 & $\sim 50.0$ & $\sim 70.0$ \\
\hline q1 & $\phi=-0.1211 z+0.5735$ & 0.927 & 1432.70 & 128.17 & $\sim 50.0$ & $\sim 70.0$ \\
\hline s1 & $\phi=-0.09536 z+0.5423$ & 0.717 & 1492.24 & 68.626 & $* *$ & $* *$ \\
\hline $\mathrm{t} 1$ & $\phi=-0.1310 z+0.5894$ & 0.792 & 1445.80 & 115.07 & 146.06 & 205.34 \\
\hline $\mathrm{t} 2$ & $\phi=-0.1355 z+0.5905$ & 0.783 & 1405.90 & 154.96 & 250.22 & 352.42 \\
\hline $\mathrm{t} 3$ & $\phi=-0.1169 z+0.5684$ & 0.910 & 1440.55 & 120.32 & 233.12 & 322.86 \\
\hline $\mathrm{t} 4$ & $\phi=-0.1258 z+0.5730$ & 0.878 & 1375.20 & 185.67 & 110.14 & 157.74 \\
\hline y1 & $\phi=-0.1175 z+0.5245$ & 0.695 & 1059.57 & 501.30 & 774.75 & 1118.7 \\
\hline y2 & $\phi=-0.1347 z+0.5936$ & 0.933 & 1437.27 & 123.60 & 441.73 & 682.13 \\
\hline
\end{tabular}

$\phi$-porosity (\%);

$z$ - depth $(\mathrm{km})$;

** - no seismic line traversing the well, or impossible to estimate the erosion on the site. 


\section{METHODS}

\subsection{Estimating Relative Uplifts}

Empirical data suggest that the maximum depth to which a rock has been buried is a measure of the irreversible effect on porosity (Telford et al. 1976). As a result, present-day porosity profiles of all given wells in a region can be used to estimate their relative uplifts (Nelson and Bird 2005), assuming that the original porosity profiles for different wells would be the same before differential uplifting. All wells so far drilled in the Xihu Depression are shown in Figs. 1 and 2. To get porosity profiles of these wells, we applied the acoustic formation factor equation (Raymer et al. 1980; Raiga-Clemenceau et al. 1988):

$$
\phi=1-\left(\Delta t_{m} / \Delta t\right)^{1 / f}
$$

in which $\phi$ is the fractional porosity, $f$ is the formation factor, $\Delta t_{m}$ and $\Delta t$ are the matrix travel time and wireline sonic log travel time, respectively. Equation 1 is considered not only empirical, but also physically meaningful (Raiga-Clemenceau et al. 1988). With predetermined $f$ and $\Delta t_{m}$, Eq. 1 converts sonic log data to porosity data. Neutron porosity logs for some wells are also available, but they are either limited to short intervals or too scattering to allow for accurate line fitting required by uplift estimation. Based on laboratory measurements, Issler (1992) determined $f=2.19$ and $\Delta t_{m}=220 \mu \mathrm{s} \mathrm{m}^{-1}$ for siliciclastic shales. These values were fully or partially adopted to different areas (Harrold et al. 1999) or to different lithologies (Nelson and Bird 2005). In this study, we combine sonic travel time and neutron porosity logging data to determine $f$ and $\Delta t_{m}$ suitable for the Xihu Depression. By taking logarithms on both sides of Eq. 1, we have:

$$
\log \Delta t=\log \Delta t_{m}-f \log (1-\phi)
$$

Thus $f$ and $\Delta t_{m}$ can be easily estimated by a least-square linear fitting of $\Delta t$ versus $1-\phi$ on double logarithmic coordinates for each individual well. Table 2 lists the estimated $f$ and $\Delta t_{m}$ for 12 wells. Excluding well s1, which is located outside of the Xihu Depression and has a very low regression coefficient, the average $f$ and $\Delta t_{m}$ are 1.396 and $195.48 \mu \mathrm{s} \mathrm{m}^{-1}$, respectively. A second method of estimating the average $f$ and $\Delta t_{m}$ is to plot $\Delta t$ versus $1-\phi$ on double logarithmic coordinates for all wells in Table 2, and do a least-square linear fitting (Fig. 5). The estimated average $f$ and $\Delta t_{m}$ are 1.382 and $193.24 \mu \mathrm{s} \mathrm{m}^{-1}$, respectively. These two values are very close to the mean values estimated from Table 2 , and are used in this paper for converting sonic travel time data to porosity data.

\subsection{Erosion Analyses}

It needs to be said that similar methods as the one used in estimating uplift have been applied to estimating absolute erosions (Magara 1976; Heasler and Kharitonova 1996; Liu et al. 
1999; Wang and Zhang 2005). Heasler and Kharitonova (1996) in particular provided a physically more realistic exponential model of sonic transit time to allow for more accurate estimations at large depth intervals. However, in the Xihu Depression, due to later deep burial of unconformity $\mathrm{T}_{1}^{0}$, which under most cases are buried at depths larger than erosion thicknesses (Liu et al. 1999), the compaction profile beneath $\mathrm{T}_{1}^{0}$ may have been altered so that accurate erosion thickness estimation may no longer be possible. So we will not proceed further in this direction. On the other hand, the widespread angular unconformities in the central inversion zone and dense multi-channel seismic coverage offer a direct and reliable method for erosion measurements by simply extrapolating the upper and lower bounds of eroded strata over the denudation area (Fig. 3). The depth difference between the upper and lower bounds gives the erosional thickness at a particular point. This is a direct and often reliable method for erosion analysis without resorting to sophisticated techniques. The success of using this method relies on accurate identifications of syn-inversion deposition and eroded sequences. These structures are fortunately easy to identify in the Xihu Depression area by truncations and onlaps on seismic sections (Fig. 6), and the dense coverage of seismic lines makes it possible to estimate the erosion at or near a well site.

Table 2. Matrix travel time and formation factors for 12 wells from the Xihu Depression.

\begin{tabular}{|c|c|c|c|c|}
\hline $\begin{array}{c}\text { Well } \\
\text { names }\end{array}$ & Depth interval (m) & $\Delta T_{m}(\mu \mathrm{s} / \mathrm{m})$ & Formation factor $(f)$ & $\mathbf{R}^{2}$ \\
\hline b1 & $1796.2-3807.1$ & 203.42 & 0.974 & 0.840 \\
\hline c9 & $1988.0-3079.0$ & 234.99 & 0.765 & 0.610 \\
\hline g1 & $1605.1-3799.9$ & 190.19 & 1.690 & 0.587 \\
\hline h2 & $2252.7-3843.6$ & 207.00 & 1.051 & 0.725 \\
\hline $\mathrm{j} 1$ & $1787.1-4511.6$ & 177.95 & 2.256 & 0.616 \\
\hline $\mathrm{n} 1$ & $1917.0-4163.0$ & 196.38 & 1.429 & 0.632 \\
\hline $\mathrm{q} 1$ & $1795.1-4516.2$ & 188.28 & 1.413 & 0.565 \\
\hline s1 & $651.10-1715.2$ & 308.16 & 0.634 & 0.177 \\
\hline $\mathrm{t} 1$ & $1820.0-4656.3$ & 185.78 & 1.462 & 0.753 \\
\hline $\mathrm{t} 2$ & $1384.3-3684.4$ & 206.86 & 0.942 & 0.528 \\
\hline yl & $1764.5-3760.0$ & 202.68 & 1.349 & 0.410 \\
\hline \multirow[t]{2}{*}{$\mathrm{y} 2$} & $1750.0-3795.0$ & 156.79 & 2.026 & 0.658 \\
\hline & $\begin{array}{c}\text { Mean } \\
\text { (without s1) }\end{array}$ & 195.48 & 1.396 & \\
\hline
\end{tabular}




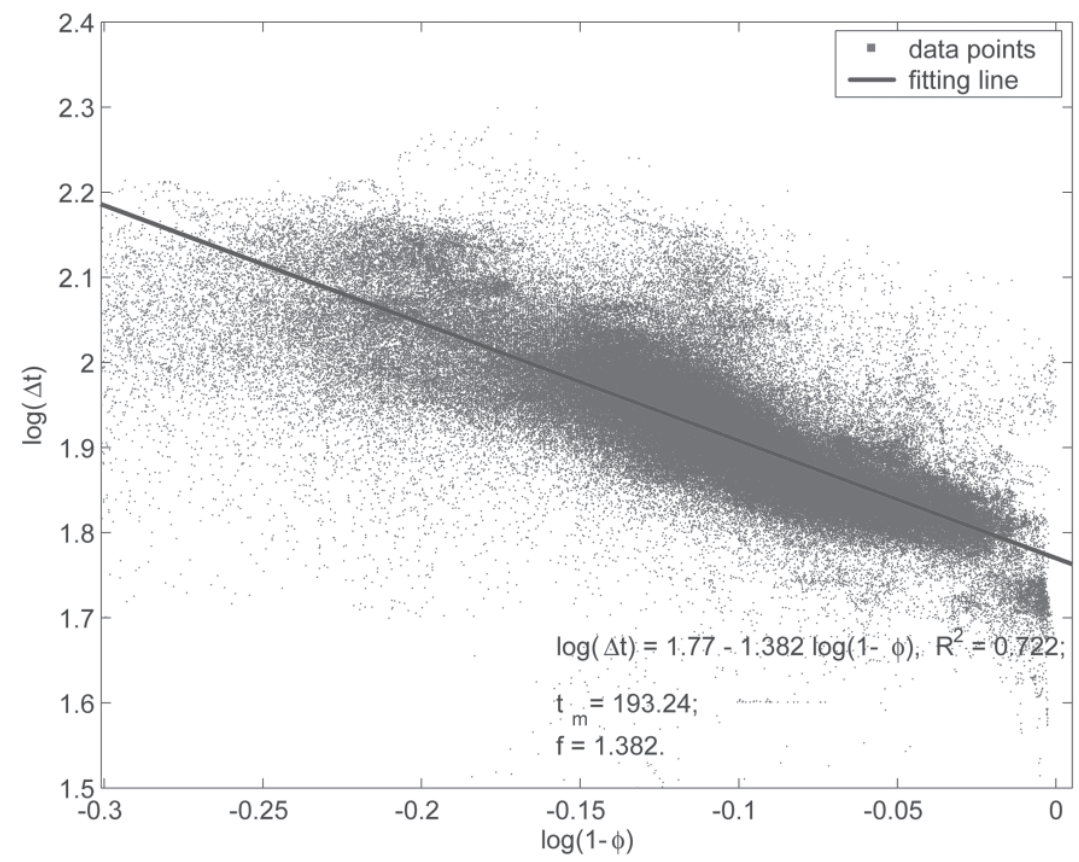

Fig. 5. Linear fitting on the double logarithmic coordinates between sonic travel time and porosities. From the fitting equation, matrix travel time and formation factor for the Xihu Depression can be estimated.

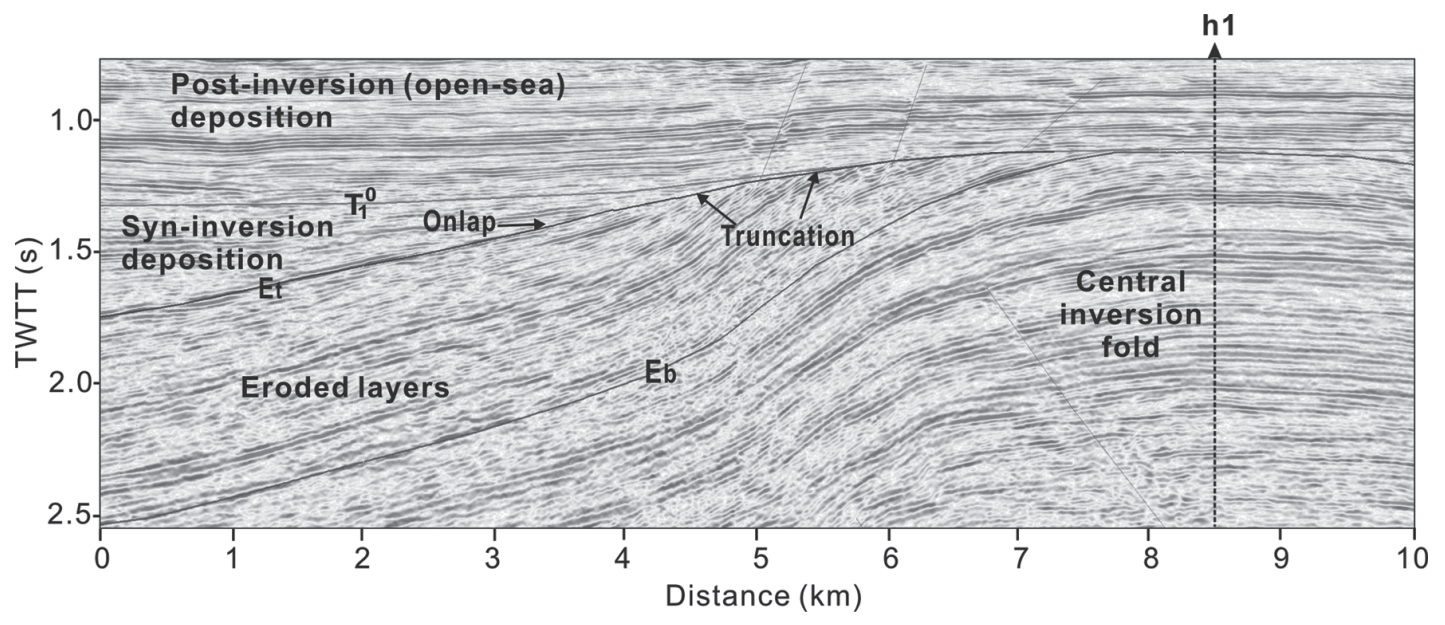

Fig. 6. Zoomed view of contact relationships of sedimentary packages, on the western flank of the inversion fold. $\mathrm{T}_{1}{ }^{0}=$ inversion unconformity. Et $=$ top of eroded strata; $\mathrm{Eb}=$ base of eroded strata; TWTT = two way travel time. See Fig. 3 for location. 


\section{RESULTS AND INTERPRETATIONS}

\subsection{Magnitudes of Relative Uplifts and Erosions}

Traditionally, porosity-depth relationships are often treated as exponential curves (Steckler and Watts 1978; Royden and Keen 1980; Sclater and Christie 1980; Sawyer 1985). However, it has been argued that for various siliciclastic rocks linear fittings on porosity versus depth data are better or sufficient (Maxwell 1964; Hunt et al. 1998; Nelson and Bird 2005). As shown in Fig. 4, the dominant rock types in the Xihu Depression are siliciclastic rocks. For wells from the Xihu Depression, we find that, for shallow depth $\leq 3.5 \mathrm{~km}$, linear fittings constantly perform better, in terms of regression coefficients, than exponential fittings. To demonstrate this, we show one example using well h1, which penetrates the central inversion fold (Figs. 3, 6). The sonic log of this well (Fig. 7a) has an exponential trend. However, the porosity curve (Fig. 7b) converted from the sonic log based on the acoustic formation factor equation (Eq. 1) can be better or sufficiently approximated with a linear trend. An exponential fit on this porosity curve leads to a regression coefficient of 0.904 , slightly smaller than the linear regression coefficient of 0.917 . Linear fitting equations of porosity versus depth for the 26 wells from the Xihu Depression are listed in Table 1. It can be noticed that most of these fittings have regression coefficients $\mathrm{R}^{2}$ larger than 0.8 , indicating fairly good linear regressions.

Figure 8 shows all the linear fitting models for the 26 wells. It is obvious that these linear models are nearly parallel to each other, indicating close porosity gradients for different wells. However, these model lines are offset, reflecting various degrees of differential uplifts. Assuming the equal porosity surface was horizontally flat before differential uplifts (tectonic inversion), the amounts of relative uplifts can be solved for a particular porosity value. Since this study centers on the erosions and relative uplifts at the unconformity $\mathrm{T}_{1}{ }^{0}$, which ranges from about 1.0 to $1.5 \mathrm{~km}$ beneath the sealevel, we choose the corresponding porosity value 0.4 for calculating relative uplifts. These calculated values are shown in Table 1. Among these wells, well c8 appears to have the least amount of uplift while the largest uplift occurred around well y1.

The structure of the unconformity $\mathrm{T}_{1}{ }^{0}$ and the contact relationships (i.e., onlaps, truncations, etc.) for different sedimentary packages around the inversion folds (Fig. 6) suggest that syninversion depositions occurred while the erosions continued around the folds. The identification of the boundary between the eroded strata and the syn-inversion strata facilitates the estimation of erosional thicknesses. Fig. 3 shows the unconformity $\mathrm{T}_{1}{ }^{0}$ and the lower and upper bounds of the eroded strata. Based on time-depth relationships of nearby wells (well h1 in this case), thicknesses of eroded strata and syn-inversion strata can be measured from the seismic sections. These thicknesses are then decompacted to reflect their original thicknesses at the time of incipient erosion before the sedimentation of strata above $\mathrm{T}_{1}^{0}$. Using the linear porosity-depth curves $\phi(z)$ shown in Table 1, decompacted thicknesses $x$ can be estimated by numerically solving the equation:

$$
\int_{0}^{x}[1-\phi(z)] d z=\int_{e t}^{e b}[1-\phi(z)] d z,
$$

in which $e b$ and $e t$ are depths of the bases and tops of eroded strata, respectively. The de- 
compacted thicknesses are also shown in Table 1. Note however, that the erosional thicknesses around some wells are not available because either there are no seismic line going through those wells or the top bounds of the eroded strata at those sites are too intangible to be easily identified. Around some wells, the erosional thicknesses appear to be so insignificant that we assign a constant value of $50 \mathrm{~m}$ (about $70 \mathrm{~m}$ after decompaction) to stand for their erosional thicknesses. Overall, the erosions we estimated are compatible with other studies (Liu et al. 1999; Wang and Zhang 2005), with a general agreement that erosions in the northern part of the central inversion zone of the Xihu Depression are larger than those estimated to the south.

If the sedimentation rates of syn-inversion strata $R_{s}$ are known, the time span of erosion can be estimated. We could use the sedimentation rate of post-inversion strata $R_{p}$ to approximate the sedimentation rate of syn-inversion strata. Based on the geometry in Fig. 3, we can write:

$$
R_{s} \approx R_{p}=h_{p} / t_{p},
$$

where $h_{p}$ is the thickness of post-inversion strata, $t_{p}$ is the time lapse after the formation of $\mathrm{T}_{1}^{0}$,

(a)

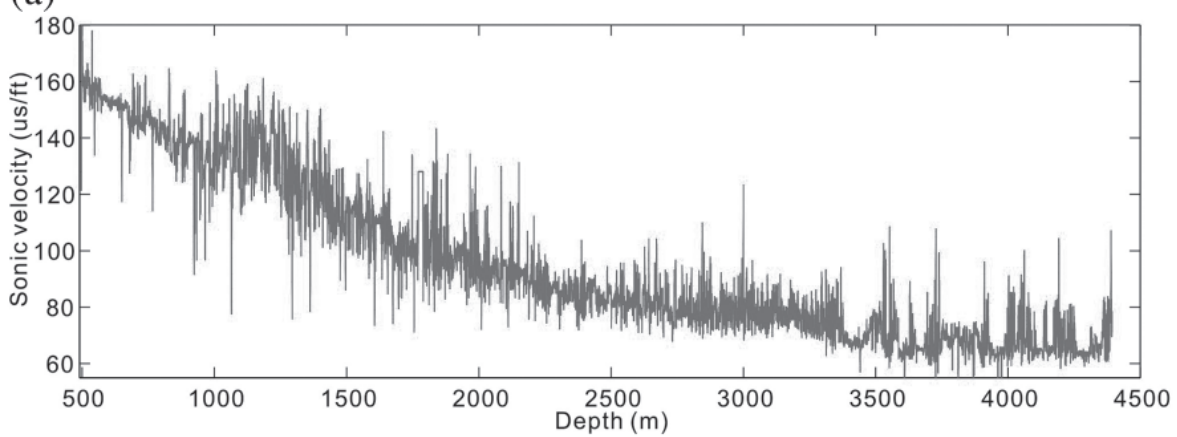

(b)

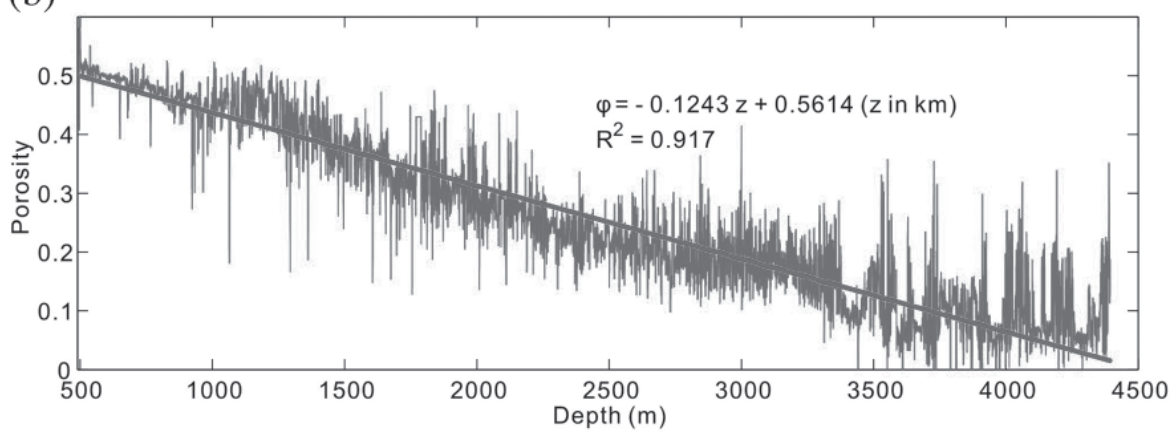

Fig. 7. Sonic log and converted porosities of well h1. Note that the porosity trend can be sufficiently approximated by a linear fit. 


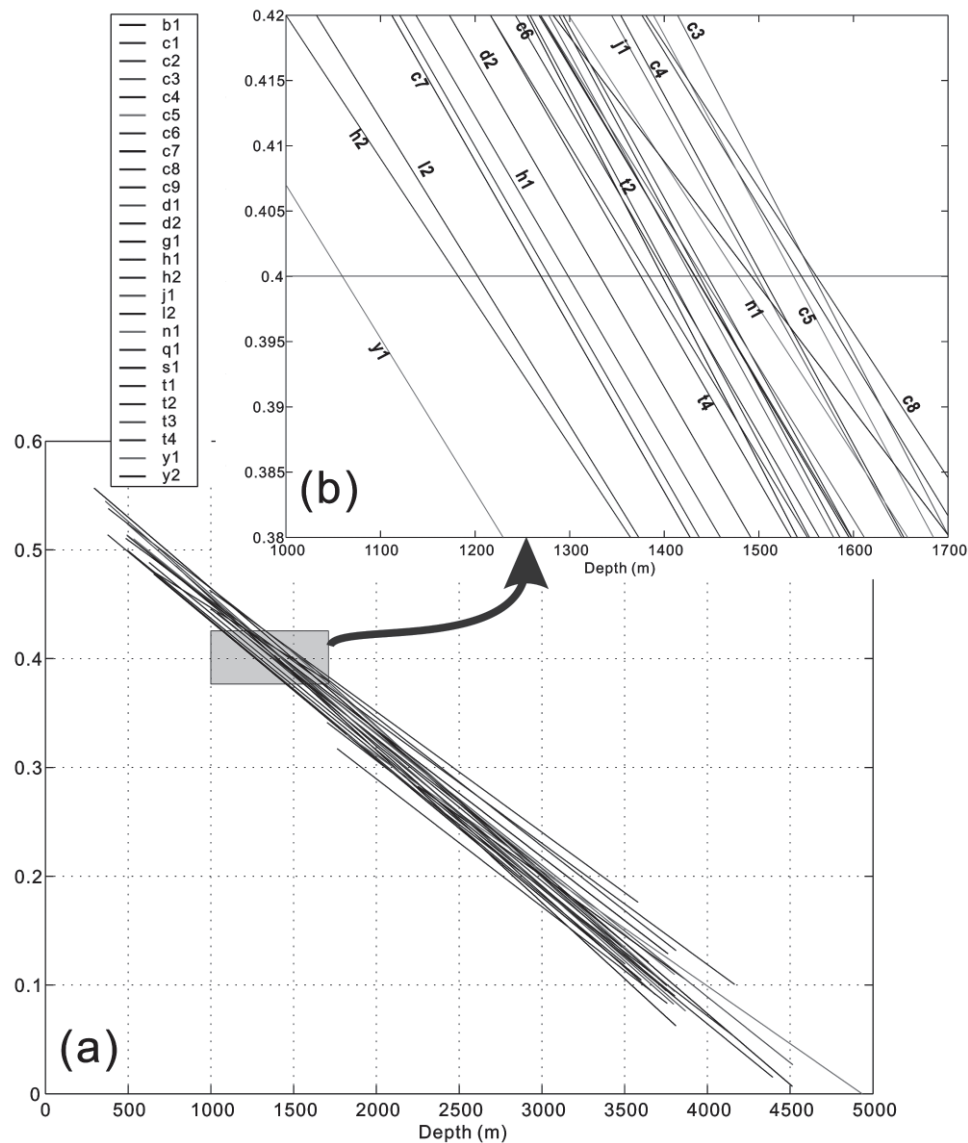

Fig. 8. (a) Linear porosity models for 26 wells. (b) Zoomed view of linear porosity models around porosity 0.4 . In the zoomed view, linear extrapolations are performed for those wells without sonic logging data around those depths. Labels for some wells are also shown in (b).

which is about 5.0 Ma. The time span of erosion $t_{e}$ shall be equal or close to the time span of syn-inversion deposition $t_{s}$, and can then be estimated by

$$
t_{e} \approx t_{s}=h_{s} / R_{s},
$$

where $h_{s}$ is the thickness of syn-inversion deposition. The erosional rate $R_{e}$ can also be estimated using:

$$
R_{e}=h_{e} / t_{e},
$$


where $h_{e}$ is the thickness of eroded strata. Based on Eqs. 4, 5, and 6, we calculated the erosional time spans and erosional rates of 10 wells (Table 3 ). The sedimentation rates of post-inversion strata $R_{p}$ appear to be close around different wells and are averaged at $0.245 \mathrm{~mm} \mathrm{a}^{-1}$. We thus come to time spans of erosion varying from 1.2 to $5.0 \mathrm{Ma}$ at different well locations. The erosional rates also appear to vary from as low as $0.113 \mathrm{~mm} \mathrm{a}^{-1}$ to as high as $0.407 \mathrm{~mm} \mathrm{a}^{-1}$. In general, it does appear that wells in the northern part of the Xihu Depression (such as wells d3, $\mathrm{h} 1, \mathrm{y} 1, \mathrm{y} 2$, and 12) experienced longer time periods of erosion at relatively higher erosional rates than some wells to the south (for example, wells c6, c7, c8, and d1). This spatial variation suggests that inversion and erosion in the Xihu Depression are diachronous. While erosions in the northern part continued, they probably ceased to the south or in other areas of minor tectonic inversions. Seismic data confirm that erosion surfaces around the central inversion zone migrate with time. Fig. 6 clearly shows that, during the fold growth, early erosional surface (horizon $\mathrm{E}_{\mathrm{t}}$ at the proximity of well h1) can be partially buried by syn-inversion deposition while erosion continued elsewhere. Fold growth during basin inversion was extensively studied by Wang et al. (1995). On the basin scale, we also notice that the inversion unconformity $\mathrm{T}_{1}{ }^{0}$ is diachronous, truncating the tops of some major inversion folds but overpassing other minor folds.

\subsection{Correlations Between Uplifts and Erosions}

Naturally one would think that uplift and erosion are positively correlated over a broad area, but to prove this statement is not easy. Very often uplifts and erosions are too subtle to be easily measured, or it is impossible to measure both quantities at the same locality. For a local point in this study area, there could be many factors causing discrepancies between erosions and uplifts, including spatial migration of inversion folds, differential inversion time and erosion rates, post-inversion local uplifting/subsidence, etc. In this study, we obtained measurements of both relative uplifts and absolute erosions around 20 wells covering most parts of the

Table 3. Estimated erosion durations $t_{e}$ and erosion rates $R_{e}$ for 10 wells from the Xihu Depression.

\begin{tabular}{ccccc}
\hline Well names & $\boldsymbol{R}_{\boldsymbol{s}}(\mathbf{m m} / \mathbf{a})$ & $\boldsymbol{t}_{\boldsymbol{e}}(\mathbf{M a})$ & $\boldsymbol{h}_{\boldsymbol{e}}(\mathbf{m})$ & $\boldsymbol{R}_{\boldsymbol{e}}(\mathbf{m m} \mathbf{a})$ \\
\hline $\mathrm{d} 3$ & 0.225 & 3.23 & 1317.49 & 0.407 \\
$\mathrm{~h} 1$ & 0.268 & 5.00 & 1700.40 & 0.340 \\
y1 & 0.249 & 2.89 & 1118.68 & 0.387 \\
y2 & 0.315 & 1.93 & 682.13 & 0.353 \\
12 & 0.284 & 3.73 & 1461.66 & 0.392 \\
c6 & 0.218 & 1.68 & 399.58 & 0.238 \\
c7 & 0.227 & 1.20 & 136.45 & 0.113 \\
c8 & 0.219 & 2.23 & 283.28 & 0.127 \\
d1 & 0.225 & 1.22 & 309.07 & 0.254 \\
g1 & 0.217 & 1.68 & 211.93 & 0.126 \\
\hline
\end{tabular}


Xihu Depression (Table 1). In Fig. 9a, both erosions and relative uplifts are plotted for each of these 20 wells. Although some exceptions are observed for several wells (notably wells c7, h2, and y2) that show unproportionate relative uplifts and absolute erosions, most wells show similar trends of variations in their erosions and relative uplifts.

The wells in Fig. 9a are lined up such that, from the left to the right of the figure, it is roughly about going from the south to the north of the Xihu Depression. It is noticeable that wells in the northern part of the Xihu Depression have higher relative uplifts that correspond to sharply increased erosions. To further examine the correlation between uplifts and erosions, we compute their cross-correlation function, which measures the similarity between two different data sequences. If two data sequences are identically the same, their normalized crosscorrelation coefficient will equal 1.0 at zero lag (Bracewell 1965). Cross correlation can be quite robust to noises in data sequences, such as noises from other geological processes or from measurement errors that could bias the overall correlation patterns between uplifts and erosions. Thus normalized cross correlation is an efficient tool for matching two data series, regardless of data scales. The cross-correlation function of uplifts and erosions for the 20 wells peaks at about 0.8 at zero lag (Fig. 9b), indicating strong correlations/similarities between them.

Although at a given locality erosion can be affected by many other factors, a high degree of cross correlation indicates that, over the broad area of the Xihu Depression, the late Pliocene erosions are strongly tectonically controlled by basin inversion. Meanwhile, a good cross correlation also confirms that sonic logging data, and thereby porosity profiles, can be effectively applied to infer relative uplifts.

To further testify and visualize the correlation between uplifts and erosions, map views on the magnitudes of relative uplifts and erosions are generated via kriging interpolation for the 20 wells in Table 1 . Because we have only a limited number of wells where both measurements of uplift and erosion are available, and because these wells are not evenly distributed, interpolations can be problematic. Even so, a good correlation between uplift and erosion can still be perceived by comparing their map views side by side (Fig. 10). From Fig. 10 it is evident that the spatial distributions of erosions and relative uplifts follow a very similar trend. Overall, the northeastern part of the depression has higher magnitudes of erosions and relative uplifts, whereas the western and southwestern part experienced lower degrees of erosions and uplifts.

Another way of looking at the relationship between erosions and relative uplifts is to plot relative uplifts versus erosions (Fig. 11). Excluding wells h2 and c7 that show quite low local erosions, there seems to be an exponential relationship between erosions and relative uplifts. Increasing uplifts tend to exponentially increase erosions on the central inversion zone of the Xihu Depression. Many erosion models so far have been proposed, including the constant rate erosion model (Stüwe 2002) and the model in which the erosion rate is linearly proportional to local relief or elevation (Ahnert 1970; Zhou and Stüwe 1994). Our studies seem to suggest that the erosion rates are exponentially proportional to uplifting rates, which in turn cause differences in local relieves. Reflection seismic data do reveal significant local relieves in the late Pliocene near wells showing strong erosions and uplifts (e.g., wells d3, 12, h1, y1). As the exact relationship between uplift and erosion are still controversial and could be affected by many other geological factors, more measurements are necessary to further attest this statement. 


\section{DISCUSSIONS AND CONCLUSIONS}

(1) Well data suggest that the average formation factor $f$ and matrix travel time $\Delta t_{m}$ in the Xihu Depression are 1.382 and $193.24 \mu \mathrm{s}^{-1}$, respectively.

(2) For depths less than $3.5 \mathrm{~km}$, porosity profiles converted from sonic travel time data can be better fitted by straight lines rather than by exponential curves. Relative uplifts estimated from linear models of porosity profiles ranges from 0.0 to $501.3 \mathrm{~m}$, based on 26 wells from the Xihu Depression.
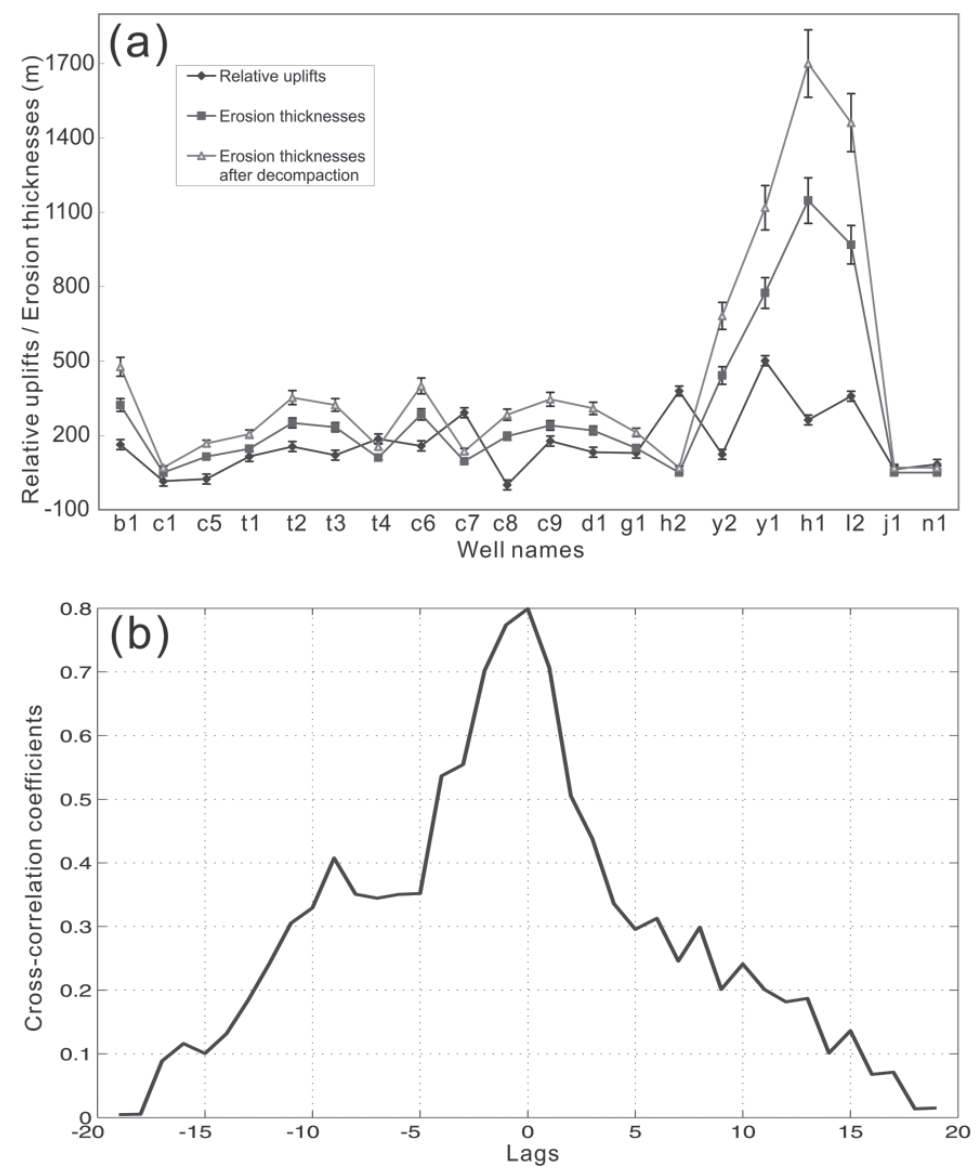

Fig. 9. (a) Relative uplifts and absolute erosions for wells from the Xihu Depression. It can be observed that except for a few wells, a positive correlation can be observed between relative uplifts and absolute erosions. (b) The normalized cross correlation function of relative uplifts and absolute erosions, which peaks at $\sim 0.8$ at zero lag, indicates strong positive correlation. 

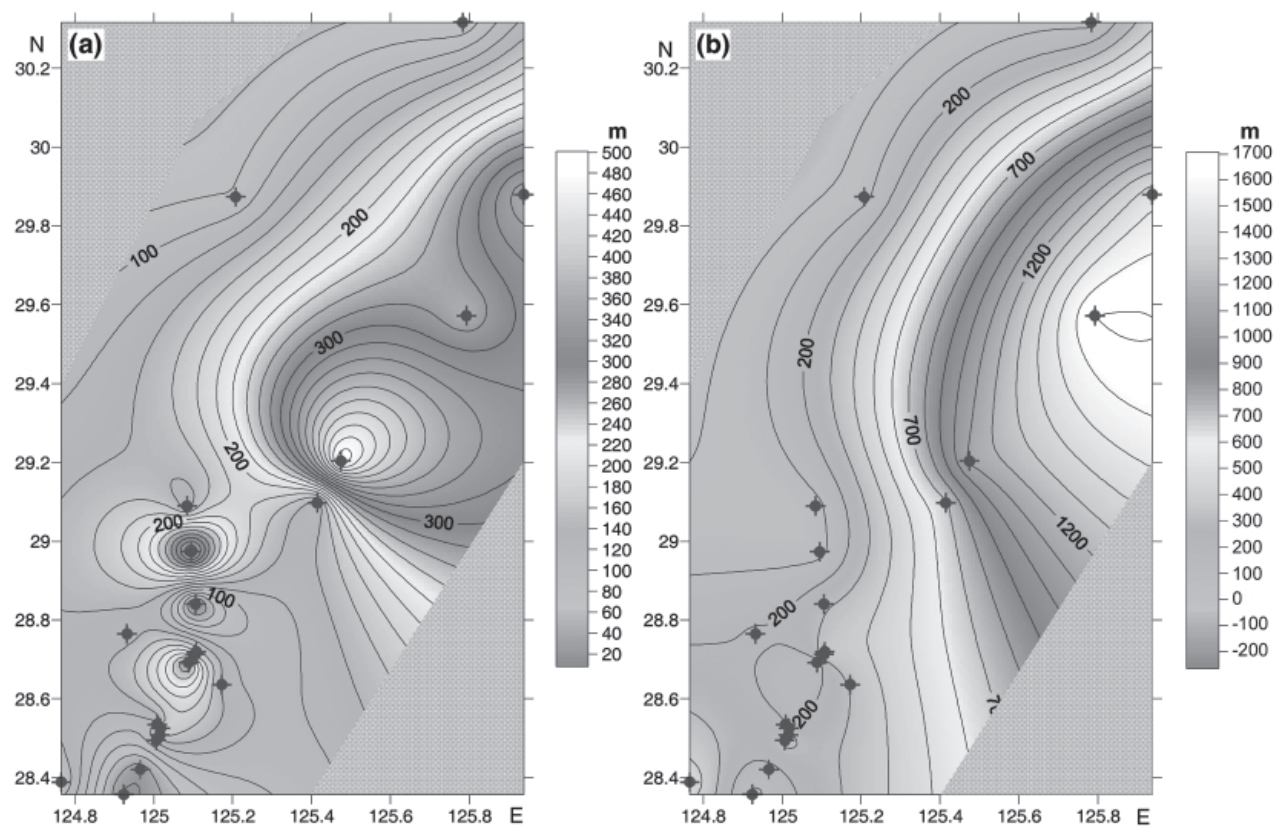

Fig. 10. Map views of relative uplifts (a) and erosion thicknesses after decompaction (b) in the Xihu Depression.

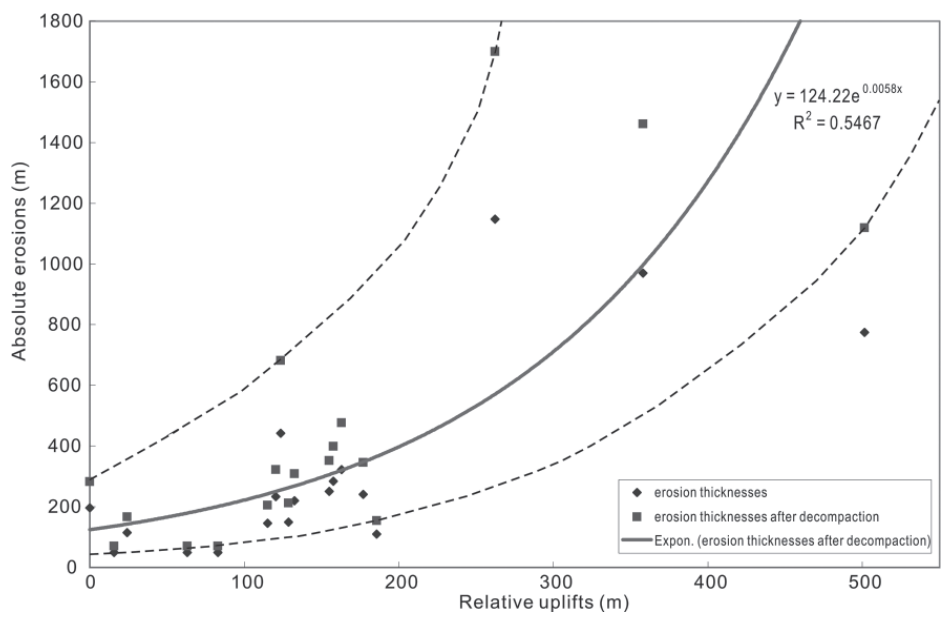

Fig. 11. Plot of relative uplifts versus absolute erosions. This graph shows erosion thicknesses, both directly estimated from seismic data and after decompaction. The exponential fit is based on erosion thicknesses after decompaction. Dashed curves are the sketched envelopes of the data. 
(3) Erosion thickness measured directly from seismic sections is normally larger than relative uplift measured at the same locality. Erosion thicknesses vary considerably, from less than 100.0 to more than $1700.0 \mathrm{~m}$.

(4) The erosional durations and erosion rates appear to be variable across the Xihu Depression. Sites with stronger uplifts normally experienced longer erosion at higher erosion rates. Seismic data also suggest that the areas exposed to erosion migrated with time, both locally and regionally, forming the diachronous unconformity $\mathrm{T}_{1}{ }^{0}$. This erosional migration produced truncations and erosional unconformity $\left(\mathrm{E}_{\mathrm{t}}\right)$ around inversion folds. The existence of $\mathrm{E}_{\mathrm{t}}$ makes it possible to identify syn-inversion depositions and facilitate the estimation of erosional thicknesses.

(5) Cross correlation analysis shows a strong positive correlation between regional relative uplifts and absolute erosions in the Xihu Depression, although for a particular well local geological processes may largely bias this overall correlation function. Since erosions and relative uplifts are independently determined by two different methods, they can crosscheck each other. A high cross correlation coefficient (about 0.8) at zero lag indicates that the relative uplifts estimated from sonic well data are reliable, and that erosions over the central inversion zone of the Xihu Depression are dependent on, and positively proportional to, uplifts.

(6) Erosions observed in the central inversion zone of the Xihu Depression seem to be more exponentially than linearly related to relative uplifts. High relative uplifts could form large local relieves that may boost erosion. Meanwhile, large denudation may trigger elastic rebound, forming a positive feedback mechanism between uplift and erosion. These processes may collectively cause erosion to be exponentially related to uplift in our study area. However, more measurements are necessary to further attest this statement.

Acknowledgements This research is sponsored by CNOOC China Limited, and by Chinese Natural Science Foundation (Grants No. 40776026, 40504016, and 40621063). Fengli Yang, Fawei Lu, Jianpei Zhang, Chunfeng Chen, Laifu Fang, Qinglin Zhang, Haisheng Cheng, and Yi Zong also participated in the project. Fig. 1 is produced with software GMT (Wessel and Smith 1995). We thank two anonymous reviewers for their very constructive comments.

\section{REFERENCES}

Ahnert, F., 1970: Functional relationships between denudation, relief, and uplift in large midlatitude drainage basins. Am. J. Sci., 268, 243-263.

Bracewell, R., 1965: The Fourier Transform and Its Applications, McGraw-Hill, Inc., 624 pp.

Cecil, M. R., N. D. Mihai, W. R. Peter, and G. C. Clement, 2006: Cenozoic exhumation of the northern Sierra Nevada, California, from (U - Th) / He thermochronology. GSA Bull., 118, 1481-1488.

Chen, Z., and H. Ge, 2003: Inversion structures and hydrocarbon accumulation in Xihu Sag, East China Sea Basin. China Offshore Oil Gas (Geol.), 17, 20-24. (in Chinese)

Harrold, T. W. D., R. E. Swarbrick, and N. R. Goulty, 1999: Pore pressure estimation from 
mudrock porosities in Tertiary basins, Southeast Asia. AAPG Bull., 83, 1057-1067.

Heasler, H. P., and N. A. Kharitonova, 1996: Analysis of sonic well logs applied to erosion estimates in the Bighorn Basin, Wyoming. AAPG Bull., 80, 630-646.

Hsu, S. K., J. C. Sibuet, and C. T. Shyu, 2001: Magnetic inversion in the East China Sea and Okinawa Trough: Tectonic implications. Tectonophysics, 333, 111-122.

Hunt, J. M., J. K. Whelan, L. B. Eglinton, and L. M. Cathles, 1998: Relation of shale porosities, gas generation, and compaction to deep overpressures in the U.S. Gulf Coast. In: Law, B. E., G. F. Ulmishek, and V. I. Slavin (Eds.), Abnormal Pressures in Hydrocarbon Environments. AAPG Mem., 70, 87-104.

Issler, D. R., 1992: A new approach to shale compaction and stratigraphic restoration, Beaufort-Mackenzie Basin and Mackenzie Corridor, Northern Canada. AAPG Bull., 76, 11701189.

Kong, F., 1998: Continental margin deformation analysis and reconstruction - evolution of the East China Sea Basin and adjacent plate interaction. Ph.D. Thesis, Dept. Geol. Sci., University of Texas at Austin, 263 pp.

Liu, J., C. Lin, and J. Xiao, 1999: Characteristics and erosions of the major Tertiary unconformities and their significance to petroleum exploration in the Xihu Trough, the East China Sea. Geoscience, 13, 432-438. (in Chinese)

Magara, K., 1976: Thickness of removed sediments, paleopore pressure and paleotemperature, southwestern part of Western Canada Basin. AAPG Bull., 60, 54-65.

Maxwell, J. C., 1964: Influence of depth, temperature, and geological age on porosity of quartzose sandstone. AAPG Bull., 48, 697-709.

Nelson, P. H., and K. J. Bird, 2005: Porosity-depth trends and regional uplift calculated from sonic logs, national petroleum reserve in Alaska, Scientific Investigations Report 20055051, US Geological Survey.

Pederson, J. L., R. D. Mackley, and J. L. Eddleman, 2002: Colorado Plateau uplift and erosion evaluated using GIS. GSA Today, 12, 4-10.

Raiga-Clemenceau, J., J. P. Martin, and S. Nicoletis, 1988: The concept of acoustic formation factor for more accurate porosity determination from sonic transit time data. Log Anal., 29, 54-60.

Raymer, L. L., E. R. Hunt, and J. S. Gardner, 1980: An improved sonic transit time-to-porosity transform. SPWLA $21^{\text {st }}$ Annual Logging Symposium Transactions, 1-13.

Riebe, C. S., J. W. Kirchner, D. E. Granger, and R. C. Finkel, 2000: Erosional equilibrium and disequilibrium in the Sierra Nevada, inferred from cosmogenic ${ }^{26} \mathrm{Al}$ and ${ }^{10} \mathrm{Be}$ in alluvial sediment. Geology, 28, 803-806.

Royden, L., and C. E. Keen, 1980: Rifting process and thermal evolution of the continental margin of eastern Canada determined from subsidence curves. Earth Planet. Sci. Lett., 51, 343-361.

Sawyer, D. S., 1985: Total tectonic subsidence: A parameter for distinguishing crust types at the US Atlantic continental margin. J. Geophys. Res., 90, 7751-7769.

Sclater, J. G., and P. A. F. Christie, 1980: Continental Stretching: An explanation of the postmid-Cretaceous subsidence of the central North Sea basin. J. Geophys. Res., 85, 37113739. 
Spotila, J. A., 2005: Applications of low-temperature thermochronometry to quantification of recent exhumation in mountain belts. Rev. Mineral. Geochem., 58, 449-466.

Steckler, M. S., and A. B. Watts, 1978: Subsidence of the Atlantic-type continental margin off New York. Earth Planet. Sci. Lett., 41, 1-13.

Stüwe, K., 2002: Geodynamics of the Lithosphere. Springer-Verlag, 449 pp.

Telford, W. M., L. P. Geldart, R. E. Sheriff, and D. A. Keys, 1976: Applied Geophysics. Camb. Univ. Press, 843 pp.

Wang, G. M., M. P. Coward, W. Yuan, S. Liu, and W. Wang, 1995: Fold growth during basin inversion - example from the East China Sea Basin. In: Buchanan, J. G., and P. G. Buchanan (Eds.), Basin Inversion. Geol. Soc. Spec. Publ., 88, 493-522.

Wang, Z., and M. Zhang, 2005: Erosion restoration of the major Cenozoic unconformities in the Xihu Depression of the East China Sea. Geol. Rev., 51, 309-318. (in Chinese)

Wessel, P., and W. H. F. Smith, 1995: New version of the Generic Mapping Tools (GMT) version 3.0 released. AGU Trans., EOS, 76, 329.

Wobus, C., A. Heimsath, K. Whipple, and K. Hodges, 2005: Active out-of-sequence thrust faulting in the central Nepalese Himalaya. Nature, 434, 1008-1011.

Zhou, S., and K. Stüwe, 1994: Modeling of dynamic uplift, denudation rates, and thermomechanical consequences of erosion in isostatically compensated mountain belts. $J$. Geophys. Res., 99, 13923-13939.

Li, C. F., Z. Zhou, H. Ge, Y. Mao, 2007: Correlations between erosions and relative uplifts from the central inversion zone of the Xihu Depression, East China Sea Basin. Terr. Atmos. Ocean. Sci., 18, 757-776, doi: 10.3319/TAO.2007.18.4.757(TT). 